\title{
CAEP/ACMU 2019 Research Abstract Awards
}

First place, Plenary Presentation, Grant Innes Research Paper and Presentation Award Jeffrey J. Perry

PL01 Prospective multicenter validation of the Canadian TIA score for predicting subsequent stroke within seven days

\section{Second place, Plenary Presentation} Ian Stiell

PL02 A randomized, controlled comparison of electrical versus pharmacological cardioversion for emergency department patients with recent-onset atrial fibrillation
Third place, Plenary Presentation, Top New

Investigator Award

Kerstin de Wit

PL03 Prevalence and clinical predictors of intracranial hemorrhage in seniors who have fallen

Fourth place, Plenary Presentation Simon Berthelot PL04 Comparison of the cost and the quality of the care provided to low acuity patients in an emergency department and a walk-in clinic

\section{Top Resident Research Abstract Award} Evan Russell

LO44 Simulation in the continuing professional development of Canadian academic emergency physicians - a national survey

\section{Top Pediatric Abstract Award}

Samina Ali

LO63 Humanoid robot-based distraction to reduce pain and distress during venipuncture in the pediatric emergency department: A randomized controlled trial

\section{Top QIPS Abstract Award}

Victoria Woolner

LO86 Improving time to analgesia administration for musculoskeletal injuries in the emergency department

\section{Top Medical Student Abstract Award J. Colin Evans}

LO72 Assessing non-technical skills in prehospital ad hoc team resuscitation

\section{Top Education Innovation Abstract Finalists}

Alexander Cormier

LO83 Quick Refresher Sessions (QRS): improving chest compression training for medical students

\section{Warren Cheung}

LO84 Ready to run the show: development of a new instrument for assessing resident competence in the emergency department

\section{Conor McKaigney}

LO85 Development of a competency based assessment tool for emergency department point of care ultrasound 


\section{CAEP-CanVECTOR Awards}

Vidushi Swarup

LO23 Identifying patient values and expectations for pulmonary embolism CT scanning in the emergency department
Leila Salehi

P113 Variability in utilization and diagnostic yield of Computed Tomography (CT) scans for pulmonary embolism among emergency physicians

\section{CAEP Resident Research Abstract Awards}

\section{Erica Lee}

LO74 Exploring emergency physicians' ability to predict patient admission and decrease consultation to admission time

\section{Marie-Pier Lanoue}

LO11 Influence of fear of falling on return to emergency department and further falls in community-dwelling elderly presenting for minor trauma

\section{Sachin Trivedi}

LO61 A national needs assessment on quality improvement and patient safety education in Canadian emergency medicine residency programs

Jake Hayward

LO29 Unexplained variation in 'To-Go' opioid prescribing across emergency departments in a large Canadian cohort

\section{Christopher Byrne}

LO64 The HEART score in predicting major adverse cardiac events in patients presenting to the emergency department with possible acute coronary syndrome: a systematic review and meta-analysis

Jessica McCallum

LO66 Solid organ donation from the emergency department - A death review

\section{Scott Odorizzi}

LO55 Signal \& noise - do professionalism concerns impact decision-making of competence committees? 


\section{CAEP/ACMU 2019 Grant Awards}

2018 Grizzly Den Grant Awardee

Shannon Fernando

The impact of frailty on outcomes in emergency department patients with sepsis - a feasibility trial

\section{EMAF Grant Awardees}

Keerat Grewal

Intracranial BLEEDing after head injury among anticoagulated elderly patients seen in the emergency department (IBLEED-ED): A population-based cohort study

Jake Hayward

Impact of emergency department opioid prescribing on substance misuse \& health outcomes

\section{CAEP-SREMI Grants}

Brett Burstein

Understanding parental preferences for shared

decision-making in the management of febrile young infants

\section{Fareen Zaver}

Identifying challenges in the transition from residency to independent practice: a longitudinal comparison of Emergency Medicine and Internal Medicine physicians
2019 Junior Investigator Awardees

Jennifer Chao

Low dose intravenous ketorolac in renal colic: a pilot study to plan a randomized controlled trial

Michael Hale

Residency selection in emergency medicine: a national program director and medical student survey

Kaif Pardhan

Perceptions of assessment and feedback: hawks, doves and impact on learning

Catherine Patocka

Does a 72-hour re-admission alert notification foster physician reflection? A mixed methods realist evaluation

Justine Soucy-Legault

Les bêtabloquants en réanimation cardiorespiratoire : une revue systématique

Justin Yan

A qualitative study to explore the patient experience with emergency department visits for hyperglycemia 